\title{
Direct Conjugation of Resveratrol on Hydrophilic Gold Nanoparticles: Structural and Cytotoxic Studies for Biomedical Applications
}

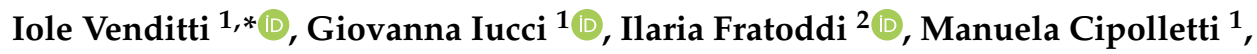 \\ Emiliano Montalesi ${ }^{1}$, Maria Marino ${ }^{1}$, Valeria Secchi ${ }^{1}\left(\right.$ ) and Chiara Battocchio ${ }^{1}$ (i) \\ 1 Department of Sciences, Roma Tre University of Rome, 00146 Rome, Italy; giovanna.iucci@uniroma3.it (G.I.); \\ manuela.cipolletti@uniroma3.it (M.C.); emiliano.montalesi@uniroma3.it (E.M.); \\ maria.marino@uniroma3.it (M.M.); valeria.secchi@uniroma3.it (V.S.); chiara.battocchio@uniroma3.it (C.B.) \\ Department of Chemistry, Sapienza University of Rome, 00185 Rome, Italy; ilaria.fratoddi@uniroma1.it \\ * Correspondence: iole.venditti@uniroma3.it; Tel.: +39-06-5733-3388
}

Received: 31 August 2020; Accepted: 18 September 2020; Published: 23 September 2020

\begin{abstract}
Strongly hydrophilic gold nanoparticles (AuNPs), functionalized with citrate and L-cysteine, were synthetized and used as Resveratrol (RSV) vehicle to improve its bioavailability. Two different conjugation procedures were investigated: the first by adding RSV during AuNPs synthesis (1) and the second by adding RSV after AuNPs synthesis (2). The two different conjugated systems, namely AuNPs@RSV1 and AuNPs@RSV2 respectively, showed good loading efficiency $(\eta \%): \eta_{1}=80 \pm 5 \%$ for AuNPs@RSV1 and $\eta_{2}=20 \pm 3 \%$ for AuNPs@RSV2. Both conjugated systems were investigated by means of Dynamic Light Scattering (DLS), confirming hydrophilic behavior and nanodimension $\left(<2 \mathrm{R}_{\mathrm{H}}>_{1}=45 \pm 12 \mathrm{~nm}\right.$ and $\left.<2 \mathrm{R}_{\mathrm{H}}>_{2}=170 \pm 30 \mathrm{~nm}\right)$. Fourier Transform Infrared Spectroscopy (FT-IR), Synchrotron Radiation induced X-Ray Photoelectron Spectroscopy (SR-XPS) and Near Edge X-ray Absorption Fine Structure (NEXAFS) techniques were applied to deeply understand the hooking mode of RSV on AuNPs surface in the two differently conjugated systems. Moreover, the biocompatibility of AuNPs and AuNPs@RSV1 was evaluated in the concentration range 1.0-45.5 $\mu \mathrm{g} / \mathrm{mL}$ by assessing their effect on breast cancer cell vitality. The obtained data confirmed that, at the concentration used, AuNPs do not induce cell death, whereas AuNPs@RSV1 maintains the same anticancer effects as the unconjugated RSV.
\end{abstract}

Keywords: gold nanoparticles; resveratrol; conjugation; immobilization; bioconjugates; drug delivery systems

\section{Introduction}

Gold nanoparticles (AuNPs) have amazing chemical-physical features that make them appealing for biotechnology and medical applications [1-5]. The advanced state of their synthetic chemistry allows strict control on shape, dimension and surface functionalization using, among others, thiols or organic molecules as capping agents that could be chemically modified to link targeting biomolecules or/and drugs [6-9].

The opportunity to conjugate molecules on nanosupports through stable interactions (e.g., electrostatic or covalent interactions) is useful for applications such as drug delivery systems (DDSs) allowing stable molecule/carrier conjugates and facilitating the bioavailability and targeted delivery of molecules [10-12]. Although there are many issues that need to be addressed, such as the biological interaction of the nanocarrier in patients, the knowledge of the molecular mechanisms that drive nanoparticle-cell interactions, the barriers to marketing related to manufacturing, costs and 
regulatory standards, today research is investing heavily in this area, particularly seeking to minimize the complexity of nanomaterials by taking into account the final form and dosage for human use, so that a formulation has the potential to be translated into clinically applicable therapies $[13,14]$. The development of an effective method for the enhancement of therapeutic agents delivery was deeply investigated, then interesting complex platforms were proposed in the literature such as, for example, functionalized AuNPs, composites between AuNPs and copolymeric micelles, core-shell systems and photonic and plasmonic hybrid materials [15-18]. The success of AuNPs largely depends on their degree of inherent toxicity and studies on the toxicological profile are discussed preceding their usage in cancer management [19]. It has been proven that the cytotoxicity of AuNPs is closely related to nanoparticle size, surface charge, and functional groups [20,21]. Moreover, the surface functionalization of gold nanoparticles is crucial for the effective utilization of these materials in health-related applications and hydrophilic molecules, such as thiols, amines or polymers, can provide a suitable way to introduce reactive functional groups that can be utilized for targeting (e.g., antibodies, peptides, aptamers) and conjugating therapeutic agents (e.g., drugs, radionuclides, photosensitizers) [22-25].

The plant-derived polyphenols, mostly found in edible vegetables and fruits, are widely reported as potential anticancer molecules [26,27]. Among others, resveratrol (trans-3,5,4'-trihydroxystilbene; RSV) deserves particular attention for the plethora of metabolic effects with potential health benefits reported in literature, which include the prevention of initiation, promotion, and progression of breast cancer [28-30]. Several action mechanisms have been suggested to be at the root of RSV anticancer effects, including the ability of high RSV concentration (i.e., $>10 \mu \mathrm{M}$ ) to reduce breast cancer cell viability [31]. Nevertheless, no clinical applications to cancer treatment have originated from this knowledge yes, probably due to the extensive metabolism which RSV undergoes in the human gut and liver after absorption, which strongly reduces its bioavailability [29,32-34]. The problem could be solved by exploiting a highly hydrophilic vehicle, such as AuNPs or liposomes, to deliver a poorly bioavailable compound, as reported for other drugs [35-41].

As reported by Thipe and collaborators [42], the combination of RSV with gold metal is an ancient medical protocol extensively used in the Indian Ayurvedic medicine, referred to as Swarna Bhasma, to treat various diseases and disorders. Nonetheless, very few scientific publications (i.e., less than 20 present in the pubmed site) addressed the efficacy of gold-conjugated RSV nanoparticles as a therapeutic agent. Most of these papers focused on the ability of RSV to maintain its antibacterial activity [43], antioxidant properties [44,45], anti-hepatoma [46], anti-breast cancer cell invasion [47], and anti-diabetic [48] effects.

In this work, AuNPs functionalized with hydrophilic capping agents, i.e., sodium citrate (cit) and L-Cysteine (L-cys), were synthesized and deeply investigated. These AuNPs were used to conjugate RSV, improving its bioavailability. Two different procedures were studied to optimize the RSV loading efficiency ( $\eta$ \%) on AuNPs: the first conjugation procedure by adding RSV in reaction mixture during the AuNPs synthesis and the second by adding RSV in AuNPs water suspension after their synthesis and purification. In this way two different conjugated systems, AuNPs@RSV1 and AuNPs@RSV2, were prepared. The best loading was obtained by AuNPs@RSV1. Deeply structural characterization of AuNPs@RSV1 and AuNPs@RSV2 was performed to confirm the RSV stability and to investigate its interaction with gold surface in the two systems. Moreover, the biocompatibility of AuNPs and AuNPs@RSV1 was evaluated in a concentration range of 1.0-45.5 $\mu \mathrm{g} / \mathrm{mL}$ by assessing their effects on breast cancer cell, MCF-7, viability.

\section{Experimental Part}

\subsection{Materials and Methods}

Sodium citrate (cit) $\left(\mathrm{Na}_{3} \mathrm{C}_{6} \mathrm{H}_{5} \mathrm{O}_{7}\right)$, L-Cysteine (L-cys) $\left(\mathrm{C}_{3} \mathrm{H}_{7} \mathrm{NO}_{2} \mathrm{~S}\right)$, tetrachloroauric(III) acid trihydrate $\left(\mathrm{HAuCl}_{4} \cdot 3 \mathrm{H}_{2} \mathrm{O}\right)$, sodium borohydride $\left(\mathrm{NaBH}_{4}\right)$, and Resveratrol (RSV) have been used as received (Merck reagent grade). 
The Bradford protein assay was purchased from Bio-Rad Laboratories (Hercules, CA, USA), as well as the chemiluminescence reagents for Western blot Clarity Western ECL Substrate. The Anti- $\alpha$-tubulin antibody was purchased from Merck (Darmstadt, D) (cat.\# T9026, clone DM1A), while the poly [ADP-ribose] polymerase 1 (PARP-1) polyclonal antibody was obtained from Cell Signalling Technologies (Leiden, NL, The Netherlands) (cat.\#9542). All the other products were from Sigma-Aldrich (St. Louis, MO, USA). Analytical and reagent grade products were used without further purification.

UV-vis spectra were run in $\mathrm{H}_{2} \mathrm{O}$ solution by using quartz cells with a Shimadzu $2401 \mathrm{PC}$ UV-vis spectrophotometer. Fourier Transform Infrared Spectroscopy (FT-IR) spectra have been recorded as films deposited by casting from water suspension, with a Bruker Vector 22 equipped with a DTGS detector and with a Specac P/N 19650 series monolayer/grazing angle accessory. The size distribution of AuNPs in $\mathrm{H}_{2} \mathrm{O}$ solution has been investigated by means of the Dynamic Light Scattering (DLS) technique by using a Brookhaven instrument (Brookhaven, NY, USA) equipped with a $10 \mathrm{~mW} H \mathrm{HeN}$ laser at a $632.8 \mathrm{~nm}$ wavelength and at a temperature of $(25.0 \pm 0.2){ }^{\circ} \mathrm{C}$. Correlation data have been acquired and fitted in analogy to our previous work [49].

Synchrotron Radiation-induced X-ray Photoelectron Spectroscopy (SR-XPS) measurements were carried out at the PM4-LowDosePES beamline at Helmholtz-Zentrum Berlin (BessyII Synchrotron Radiation facility), allowing for a lower flux on the sample, mandatory to avoid damaging biomolecules conjugated to AuNPs. This soft X-ray bending magnet beamline is equipped with a Plane Grating Monochromator operating in collimated light (collimated PGM). The LowDose PES end-station is equipped with a SES100 hemispherical analyzer, whose Energy Resolution was estimated as $0.2 \mathrm{eV}$. A photon energy of $586 \mathrm{eV}$ was used for C1s, S2p, Au4f, N1s and O1s spectral regions with energy resolution $\mathrm{NE}=0.22 \mathrm{eV}$. Calibration of the energy scale was made referencing all the spectra to the gold Fermi edge of an Au reference sample, and the Au4f $\mathrm{f}_{7 / 2}$ signal related to metallic gold was always found at $83.9 \mathrm{eV}$. Curve-fitting analysis of the C1s, O1s, S2p, Au4f, N1s spectra was performed using Gaussian curves as fitting functions. The $S 2 \mathrm{p}_{3 / 2,1 / 2}$ doublet was fitted by using the same full width at half maximum (FWHM) for both components, a spin-orbit splitting of $1.2 \mathrm{eV}$, and a branching ratio $\left(\mathrm{S} 2 \mathrm{p}_{3 / 2} / \mathrm{S} 2 \mathrm{p}_{1 / 2}\right)$ of 2 . For Au4f $\mathrm{f}_{7 / 2,5 / 2}$ doublet, a splitting of $3.6 \mathrm{eV}$, a branching ratio Au4f $\mathrm{f}_{7 / 2} / \mathrm{Au} 4 \mathrm{f}_{5 / 2}$ of $4 / 3$ and the same FWHM values for both spin-orbit components were used. When several different species were identified in a spectrum, the same FWHM value was used for all individual photoemission bands.

Near Edge X-ray Absorption Fine Structure (NEXAFS) spectroscopy experiments were performed at the ELETTRA storage ring at the BEAR (bending magnet for emission absorption and reflectivity) beamline, installed at the left exit of the 8.1 bending magnet exit. The apparatus is based on a bending magnet as a source, a beamline optics delivering photons from $5 \mathrm{eV}$ up to about $1600 \mathrm{eV}$ with selectable degree of ellipticity. The carbon K-edge spectra were collected at normal $\left(90^{\circ}\right)$, magic $\left(54.7^{\circ}\right)$ and grazing $\left(20^{\circ}\right)$ incidence angles of the linearly polarized photon beam with respect to the sample surface. The photon energy and resolution were calibrated and experimentally tested at the $\mathrm{K}$ absorption edges of $\mathrm{Ar}, \mathrm{N}_{2}$ and Ne. The spectra were then normalized subtracting a straight line that fits the part of the spectrum below the edge and assessing to 1 the value at $330.00 \mathrm{eV}$.

\subsection{Synthesis and Purification of $A u N P s$}

The AuNPs stabilized with cit and L-cys have been prepared and characterized in analogy to literature reports [50,51]. Briefly: $1.47 \mathrm{~g}$ of cit $(0.01 \mathrm{M})$ was dissolved in $50 \mathrm{~mL}$ of distilled water, $0.006 \mathrm{~g}$ of L-cys $(0.002 \mathrm{M})$ in $25 \mathrm{~mL}$ and finally $0.42 \mathrm{~g}$ of tetrachloroauric acid $(0.05 \mathrm{M})$ in $25 \mathrm{~mL}$ of water. $25 \mathrm{~mL}$ of L-cys solution, $10 \mathrm{~mL}$ of cit solution and $2.5 \mathrm{~mL}$ of tetrachloroauric acid solutions were added sequentially in a $100 \mathrm{~mL}$ flask, provided with a magnetic stir. The solution was degassed with Argon for $10 \mathrm{~min}$, then $4 \mathrm{~mL}$ of sodium borohydride solution $(0.0030 \mathrm{~g}$ in $4 \mathrm{~mL}, 0.00008 \mathrm{~mol})$ were added. The mixture was allowed to react at room temperature for $2 \mathrm{~h}$ and at the end the brown solid was recollected and purified by centrifugation (13,000 rpm, $10 \mathrm{~min}, 4$ times with deionized water). AuNPs: UV-vis $\left(\lambda_{\max }[\mathrm{nm}], \mathrm{H}_{2} \mathrm{O}\right): 550 \mathrm{~nm}$. 


\subsection{AuNPs@RSV Preparations and Characterizations}

Two different procedures were investigated to optimize the RSV loading. (1) AuNPs@RSV1: conjugation by chemical adsorption during AuNPs synthesis; AuNPs synthesis was carried out following the same procedures but including RSV water solution $(1 \mathrm{~mL} 0.02 \mathrm{M})$ in the reagent mixture. All tests were performed in triplicate [52]. (2) AuNPs@RSV2: conjugation by physical adsorption on AuNPs post their synthesis: AuNPs and RSV (AuNPs/RSV $=1 / 2 w / w)$ were mixed and stirred at room temperature for $4 \mathrm{~h}$. At the end of the contact time, the solutions were centrifuged for $30 \mathrm{~min}$ $\left(20^{\circ} \mathrm{C}, 13,000 \mathrm{rpm}\right)$. All tests were performed in triplicate. The loading and the loading efficiency $(\eta)$ were calculated by using calibration curves, as reported in the (Supporting Information Figure S1) and calculated in reference to our previous works [40,52]. For each sample, three independent measurements were carried out and the mean value and standard deviation are reported.

\subsection{Cell Lines and In Vitro Assays}

\subsubsection{Cell Culture and Stimulation}

Human breast cancer cells MCF-7 (ATTC, LGC Standards S.r.l., Milano, Italy) were grown in air containing $5 \% \mathrm{CO}_{2}$ in modified, phenol red-free, Dulbecco's Modified Eagle's Medium (DMEM) medium. Ten percent (vol/vol) of charcoal-stripped fetal calf serum, L-glutamine (2 mM), gentamicin $(0.1 \mathrm{mg} / \mathrm{mL})$, and penicillin $(100 \mathrm{U} / \mathrm{mL})$ were added to the media before use. Cells were used at passage 13-17. The cell line authentication was periodically performed by amplification of multiple short tandem repeat loci by BMR genomics S.r.l (Padova, Italy). Cells were treated for $48 \mathrm{~h}$ with either vehicle (ethanol [EtOH]/DMEM, 1:10; vol/vol) or 17 $\beta$-estradiol (E2, $10 \mathrm{nM})$ as cell growth inducer (positive control) or Staurosporine (STS, 10 or $100 \mathrm{nM}$ ) as cell death inducer (negative control) or RSV (0.1-10 $\mu \mathrm{M})$ or AuNPs (1, 3, 9.1, 45.5, 91 and $910 \mu \mathrm{g} / \mathrm{mL})$ or AuNPs@RSV1 (9.1, 45.5 and $91 \mu \mathrm{g} / \mathrm{mL})$.

\subsubsection{Western Blot Assay}

Briefly, after the treatments, cells were lysed and protein were solubilized in the YY buffer ( $50 \mathrm{mM}$ HEPES at pH 7.5, 10\% glycerol, $150 \mathrm{mM} \mathrm{NaCl}, 1 \%$ Triton X-100, 1 mM EDTA, and 1 mM EGTA) containing $0.70 \%(\mathrm{wt} / \mathrm{vol})$ sodium dodecyl sulfate (SDS). Total proteins were quantified using the Bradford protein assay. Solubilized proteins $(20 \mu \mathrm{g})$ were resolved by $7 \%$ or $15 \%$ SDS-polyacrylamide gel electrophoresis at $100 \mathrm{~V}$ for $1 \mathrm{~h}$ at $24.0^{\circ} \mathrm{C}$ and then transferred to nitrocellulose with the Trans-Blot Turbo Transfer System (Bio-Rad) for $10 \mathrm{~min}$. The nitrocellulose was treated with $5 \%(\mathrm{wt} / \mathrm{vol})$ bovine serum albumin in $138.0 \mathrm{mM} \mathrm{NaCl}, 25.0 \mathrm{mM}$ Tris, $\mathrm{pH}$ 8.0, at $24.0^{\circ} \mathrm{C}$ for $1 \mathrm{~h}$ and then probed overnight at $4.0^{\circ} \mathrm{C}$ with anti-PARP-1 (final dilution, 1:1000) antibody. Moreover, anti- $\alpha$-tubulin (final dilution, $1: 30,000)$ antibody was used to normalize the protein loaded. The antibody reaction was visualized with the chemiluminescence western blot analysis detection reagent (Amersham Biosciences, Little Chalfont, UK). The densitometric analyses were performed by the ImageJ software for Microsoft Windows (National Institute of Health, Bethesda, MD, USA).

\subsubsection{Propidium Iodide (PI) Assay}

After being grown up to $80 \%$ confluence in 96-well plate, MCF7 cells were treated as reported above. Fixation and permeabilization were performed through ice cold EtOH $70 \%$ for $15 \mathrm{~min}$ at $-20^{\circ} \mathrm{C}$. After EtOH solution removal, the cells were incubated with PI buffer for $30 \mathrm{~min}$ in the dark. Again, solution removal was performed, and the cells were rinsed with PBS solution. The fluorescence was revealed (excitation wavelength: $537 \mathrm{~nm}$; emission wavelength: $621 \mathrm{~nm}$ ) with TECAN Spark $20 \mathrm{M}$ multimode microplate reader (Life Science, Italy). 


\subsubsection{Statistical Analysis.}

The statistical analyses were performed by Student's $t$-test, to compare two sets of data, or by ANOVA followed by Bonferroni test, to compare different group of data, by INSTAT software system for Windows. In all cases, $p<0.05$ was considered significant.

\section{Results and Discussion}

\subsection{Synthesis and Characterizations of AuNPs and AuNPs@RSV}

Highly hydrophilic AuNPs were synthetized using cit and L-cys as capping agents (see Figure 1a) to assure water dispersion by cit and modulation of size by L-cys. Moreover, both of these molecules are biocompatible and are widely used for biotechnological applications, as reported in several recent papers $[53,54]$. UV-vis spectrum in water confirmed AuNPs nanodimension and hydrophilia, showing a typical localized surface plasmon resonance (LSPR) at $550 \mathrm{~nm}$, (see Figure 1b). This result revealed that these AuNPs are particularly suitable for drug delivery, being able to act as a vehicle for biologically active but minimally hydrophilic and therefore minimally bioavailable molecules [37].

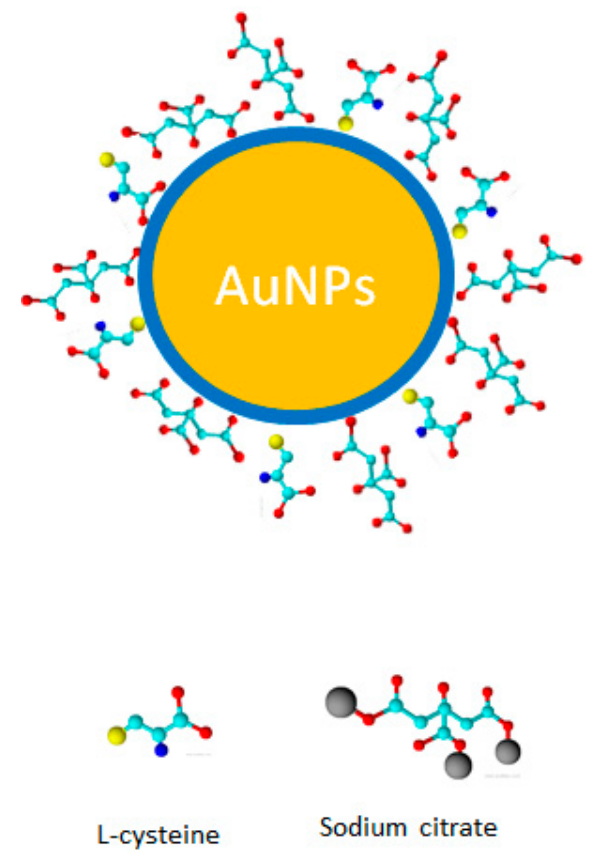

(a)

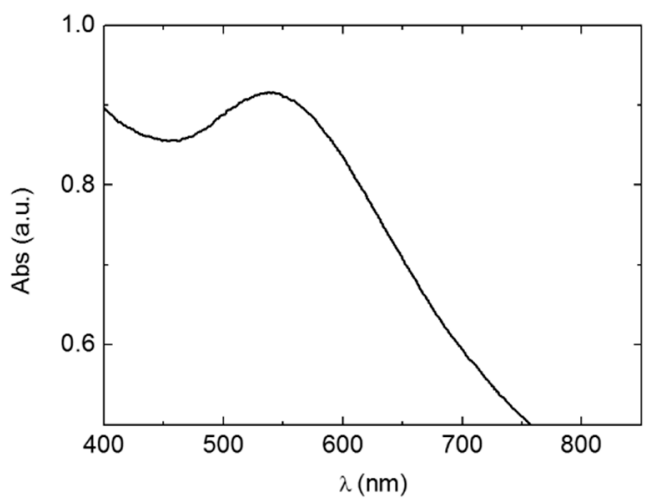

(b)

Figure 1. (a) Scheme of gold nanoparticles (AuNPs); (b) AuNPs Uv-vis spectrum in water with Table $550 \mathrm{~nm}$.

The loading protocols for AuNPs and the RSV were performed following two different approaches to compare and optimize the load: (1) direct interaction during the synthesis or (2) interaction post synthesis, giving as products the AuNPs@RSV1 and AuNPs@RSV2 respectively.

Both approaches have advantages and disadvantages. The loading of the drug carried out by incorporating RSV into the synthesis mixture allows a greater interaction with the metal particles that are gradually formed and that are immediately in contact both with RSV and with the capping agents, at the same time. The drawback could be a degradation of resveratrol under the strongly reducing conditions of the synthesis of AuNPs using sodium borohydride.

From this point of view, the post synthesis loading is safer and more conservative than the first approach. However, it has the disadvantage of putting the particles already covered by capping agents in contact with the RSV: surely, the interaction between the golden surface and the RSV is expected to 
be less effective. Of course, if the interaction occurred between the capping agent and RSV and not between gold nanoparticles surface and RSV, the problem would be overcome.

For this reason, the two approaches have been developed and studied from a structural point of view using surface-sensitive techniques, that allow to probe the interface between RSV and AuNPs. Keeping the contact conditions similar, especially regarding concentrations, time and temperature, a different load efficiency was observed, strongly in favour of the contact approach during the synthesis. The value of the loading efficiency $\eta(\%)$, reported in Figure 2a, can be calculated as follows [52]:

$$
\eta(\%)=\left(m_{\text {loaded drug }} / \mathrm{m}_{\text {drug }}\right) \times 100
$$

where $\mathrm{m}_{\text {loaded drug }}$ is the drug mass loaded on AuNPs and $\mathrm{m}_{\text {drug }}$ is the mass of drug used in the loading procedure. Figure 2a shows the $\eta(\%)$ for the two systems in comparison: AuNPs @ RSV1 produces $\eta$ $(\%)=80 \%$ and AuNPs @ RSV1 has $\eta(\%)=20 \%$.

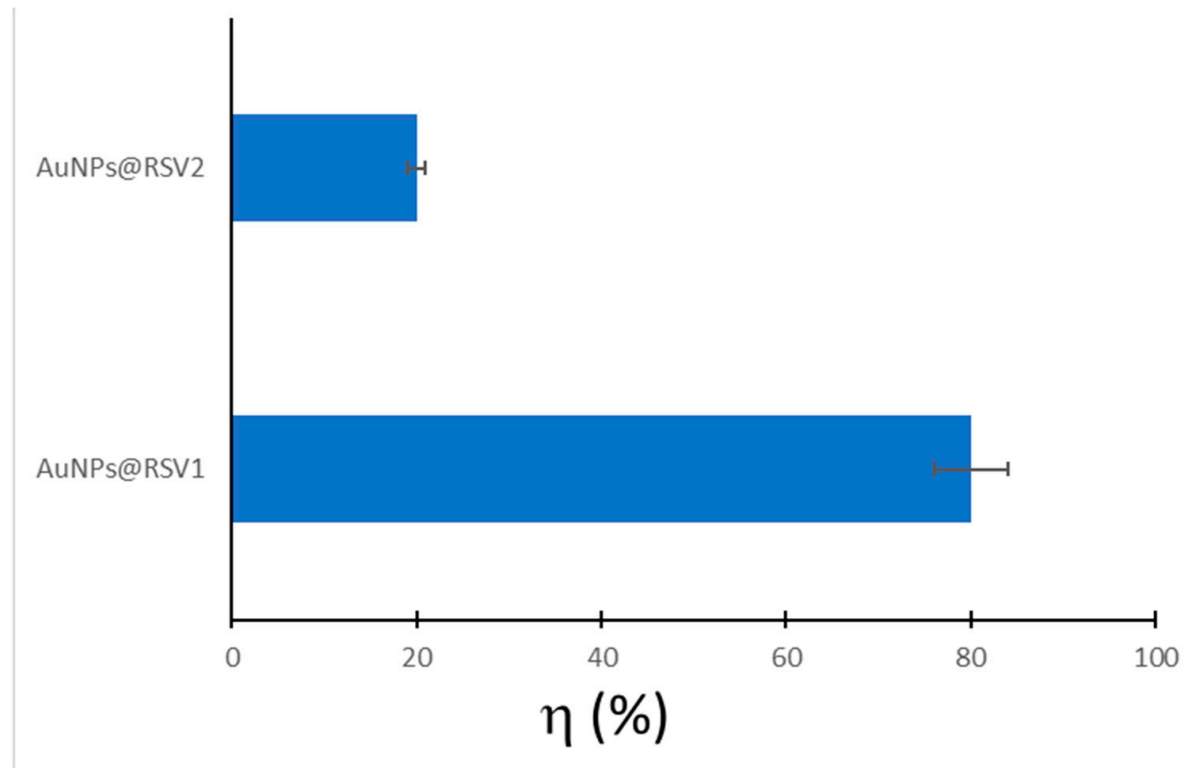

(a)

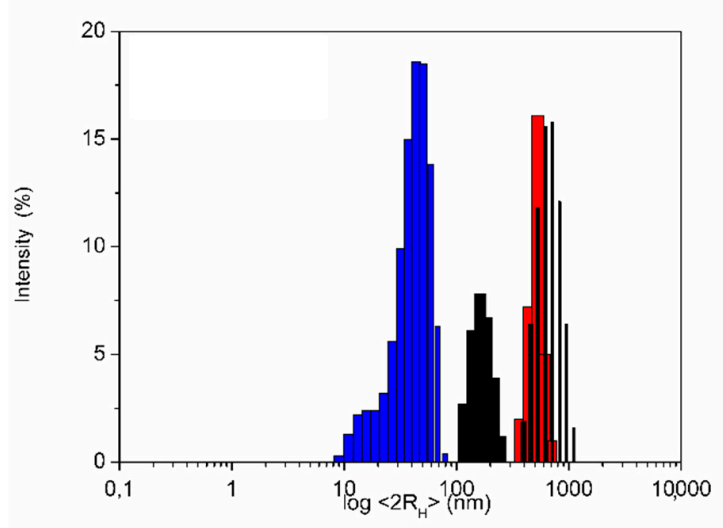

(b)

Figure 2. (a) Loading efficiency $\eta(\%)$ for AuNPs@RSV1 $(\eta(\%)=80 \pm 5 \%)$ and AuNPsRSV2 $(\eta(\%)=$ $20 \pm 3 \%) ;(\mathbf{b})<2 R_{\mathrm{H}}>$ in water of AuNPs in red (530 $\left.\pm 60 \mathrm{~nm} \mathrm{~nm}\right)$, AuNPs@RSV1 in blue (45 $\left.\pm 12 \mathrm{~nm}\right)$ and AuNPs@RSV2 in black (170 \pm 30 nm).

Both systems were characterized in depth to understand the chemical interaction between AuNPs and RSV. DLS studies were performed in a water suspension and showed a dimensional increase for 
AuNPs@RVS1 and AuNPs@RSV2, compared with the AuNPs alone, as reported in Figure 2b. In fact, the conjugation involves a different degree of hydration of the particles and induces differences in hydrodynamic diameter $\left(<2 R_{H}>\right)$, as reported in literature [49]. Moreover, the presence of the RSV during the synthesis does not affect the hydrophilic properties of the AuNPs and on the contrary induces their greater stabilization: since during the synthesis they encounter more capping agents, cit, L-cys and RSV, the dimensions are smaller and the system more monodisperse.

These first features of the two conjugated systems, which present both dimensional and RSV loading differences, highlighted the importance of deepening the study from the structural point of view of the AuNPs-RSV interaction, which is also important for the subsequent biological application.

\subsection{Structural Characterizations of AuNPs and AuNPs@RSV}

\subsubsection{SR-XPS Characterization}

The high spectral resolution and photon flux of synchrotron radiation-induced XPS are extremely well suited to investigate the interaction at the interface between thiols and gold, allowing to probe the chemistry occurring at the headgroup-metal interface in capped nanoparticles. Moreover, the high resolution of SR-XPS measurements allows to individuate signal components related to the same chemical element belonging to different functional groups, providing essential information about the composition of complicated systems such as AuNPs@RSV1 and AuNPs@RSV2. SR-XPS experiments were carried out at the C1s, O1s, S2p, N1s and Au4f core levels on AuNPs@RSV1 and AuNPs@RSV2 deposited onto a $\mathrm{TiO}_{2} / \mathrm{Si}(111)$ wafer surface by following a drop-casting procedure. Due to the complex chemical composition of the functionalized nanoparticles, pristine RSV and AuNPs deposited with the same procedure onto $\mathrm{TiO}_{2} / \mathrm{Si}(111)$ wafer surfaces were also measured; the obtained data were used as standard for the interpretation of the signals arising by the functional NPs, as described in detail in the following. $\mathrm{C} 1 \mathrm{~s}, \mathrm{O} 1 \mathrm{~s}, \mathrm{~N} 1 \mathrm{~s}, \mathrm{Au} 4 \mathrm{f}$ and $\mathrm{S} 2 \mathrm{p}$ spectra were analyzed by following a peak-fitting procedure, allowing to individuate the components arising by chemical elements with different atomic environment (i.e., in different functional groups); all peak positions BE (Binding Energies), FWHM values, atomic ratios (relative intensities) and assignments are reported in Supporting Information Table S1.

C1s spectra of AuNPs, RSV and AuNPs@RSV1 and AuNPs@RSV2 are reported in Figure 3; the AuNP spectrum (Figure 3a) appears composite and at least five spectral components can be individuated by following a peak-fitting procedure: the peak at lower BE $(285.0 \mathrm{eV})$ is due to aliphatic $\mathrm{C}-\mathrm{C}$ groups of citrate and impurities, always found on samples prepared in air; the peak at about $286.8 \mathrm{eV}$ is attributed to $\mathrm{C}-\mathrm{OH}$ functional groups of citrate and $\mathrm{C}-\mathrm{N}$ groups of cysteine; the contribution at $288.4 \mathrm{eV}$ is attributed to $\mathrm{COOH}$ end groups of cysteine and the signal at about $290 \mathrm{eV}$ is associated with carboxylate groups of citrate; the last component of low intensity is due to impurities on the sample surface $[55,56]$. Res C1s spectrum, reported in Figure $3 b$ ), shows as expected a main peak at $284.70 \mathrm{eV}$ associated with C-C aliphatic, a component around $286.40 \mathrm{eV}$ due to $\mathrm{C}-\mathrm{OH}$ groups, and a small contribution at higher $\mathrm{BE}$ values $(288.4 \mathrm{eV})$ attributed to oxidized carbon-containing contaminants on the sample surface. As for the C1s spectrum of AuNPs@RSV1 (Figure 3c), four components can be individuated, and interpreted as resulting from contributions from the two previously described signals. The first peak, centered at $285.0 \mathrm{eV}$, is attributed to a mix of aliphatic and aromatic C-C arising by AuNPs (citrate $\mathrm{C}-\mathrm{C}$ aliphatic) and Res (aromatic C); actually, this signal is larger (FWHM $=2.17 \mathrm{eV}$ ) than the $\mathrm{C}-\mathrm{C}$ signals observed for AuNPs $(\mathrm{FWHM}=1.81 \mathrm{eV})$ and Res $(\mathrm{FWHM}=1.54 \mathrm{eV})$, as expected since aliphatic and aromatic $\mathrm{C}-\mathrm{C}$ differs for $0.3 \mathrm{eV}$. The component at $286.60 \mathrm{eV}$ is still assigned to $\mathrm{C}-\mathrm{OH}$ groups, and, alike the $\mathrm{C}-\mathrm{C}$ peak, is more intense than the same feature observed for the AuNPs and Res spectra. The third and fourth components (288.4 eV and $290.3 \mathrm{eV} \mathrm{BE})$ are associated with carboxyl groups of the cysteine and citrate molecules, as in AuNPs, and are here less intense (due to the intensity growth of $\mathrm{C}-\mathrm{C}$ and $\mathrm{C}-\mathrm{OH}$ signals). Finally, the C1s spectrum of AuNPs@RSV2 (reported in Figure 3d) has almost the same shape as the C1s spectrum of pristine RSV; by applying the peak 
fitting procedure, three components can be individuated, with BE values analogous to those already described for RSV; noticeably, the two spectra differ for the intensity of the C-OH component, which is depressed in AuNPs@RSV2 due to the enhancement of $\mathrm{C}-\mathrm{C}$ and $\mathrm{COOH}$ signals, due to cysteine and citrate molecules. The very small contribution of citrate and cysteine signals to the AuNPs@RSV2 C1s spectrum is due to the steric hindrance of RSV molecules, which aggregate on the AuNPs surface as an external shell; this hypothesis is in excellent agreement with the synthetic procedure consisting of the adding of RSV after the complete capping of AuNPs with cysteine and citrate. The permanence of all RSV-related signals in both AuNPs@RSV systems clearly indicates that RSV molecules interact with AuNPs with weak chemical forces, then the molecular structure and functional groups of RSV are fully conserved in the adduct formation; this observation is crucial in order to evaluate the maintaining of the resveratrol biological activity.
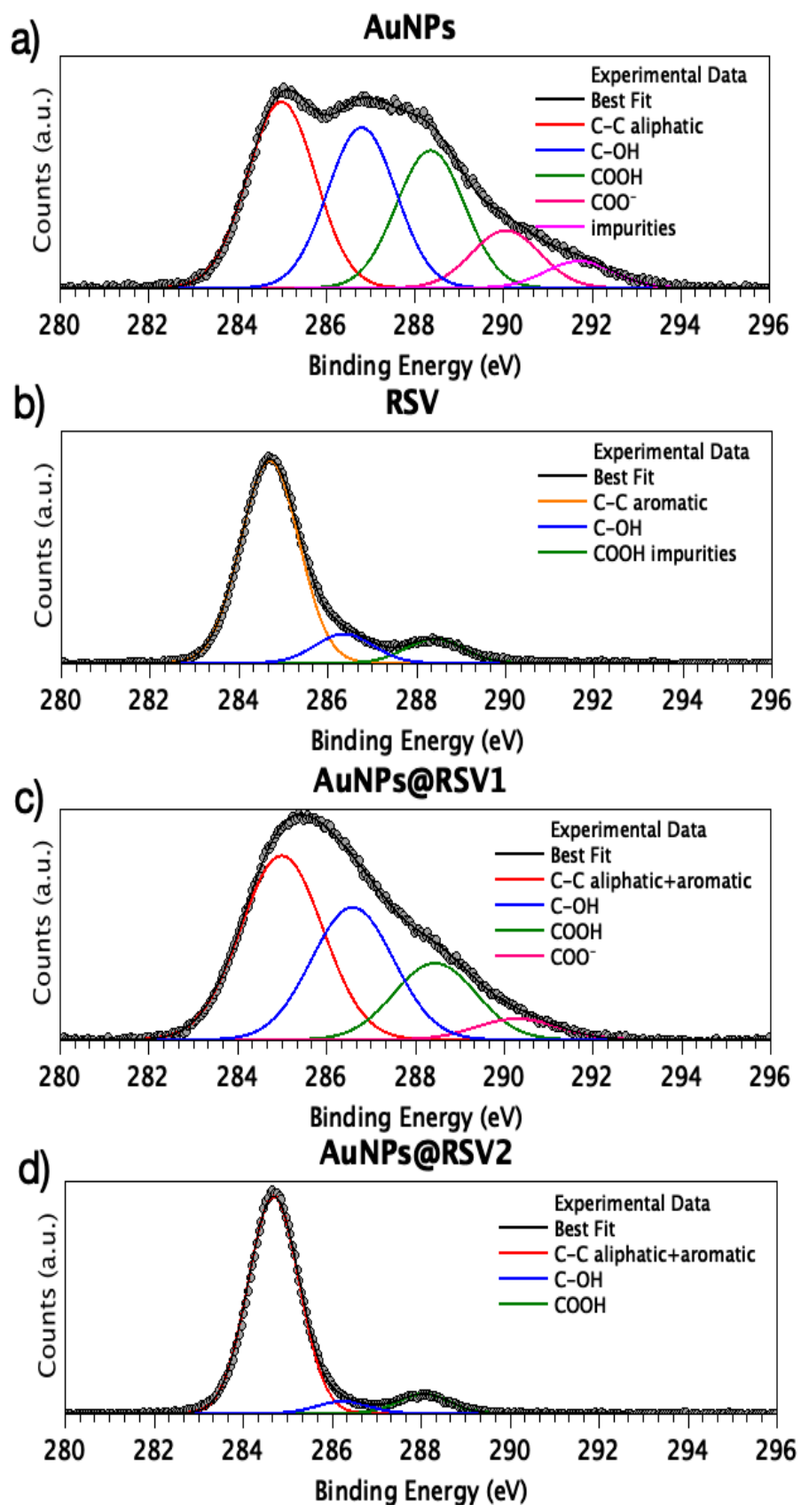

Figure 3. C1s spectra of (a) AuNPs, (b) Resveratrol (RSV), (c) AuNPs@RSV1 and (d) AuNPs@RSV2. 
SR-XPS analysis of all other core level signals confirms the chemical and molecular stability of AuNPs upon interaction with RSV in both conjugated systems, as well as the absence of strong chemical interactions between RSV molecules and stabilized gold nanoparticles surface. As an example, O1s, N1s, S2p and Au4f spectra collected on AuNPs@RSV1 are reported in the Supporting Information Figure S2. To summarize, all O1s signals show two spectral components indicative of organic-like oxygen at about $532 \mathrm{eV}$ (always assigned to $\mathrm{C}=\mathrm{O}$ functional groups of citrate and cysteine) and at nearly $533 \mathrm{eV}$ respectively, indicative of -OH groups arising by RSV [55-57] as reported in Supporting Information Table $\mathrm{S} 1$, the atomic ratio $\mathrm{C}=\mathrm{O} / \mathrm{C}-\mathrm{OH}$ decreases, as expected, as the $\mathrm{RSV}$ molecules are grafted to the AuNPs (AuNPs: $\mathrm{C}=\mathrm{O} / \mathrm{C}-\mathrm{OH}=3.0 / 1.0$, AuNPs@RSV1: $\mathrm{C}=\mathrm{O} / \mathrm{C}-\mathrm{OH}=2.3 / 1.0$ ). N1s spectra of AuNPs and AuNPs@RSV1, AuNPs@RSV2 have two components both indicative of cysteine presence and stability: a main signal at about $399.2 \mathrm{eV}$ due to ammine terminal groups of cysteine, and a small peak at $400.7 \mathrm{eV}$ usually attributed to charged amine groups [50,56]. As for S2p spectra, the B.E. position of $S 2 p_{3 / 2}$ signal, taken as reference for the $S 2 p_{3 / 2-1 / 2}$ spin-orbit pair, indicates whether the sulfur atom is covalently bonded to the metal surface or not. For thiols chemisorbed on metals, as well as for thiols covalently bonded to metal nanoparticles surface, an S2 $\mathrm{p}_{3 / 2}$ BE value of nearly $161.5 \mathrm{eV}$ is expected [58]; S2 $\mathrm{p}_{3 / 2}$ signals around $163 \mathrm{eV}$ are usually assigned to physisorbed thiols or thiolates [58]. Both components are observed for all nanoparticles samples, suggesting that the cysteine interaction with gold atoms at NPs surface is stable and not affected by the AuNPs functionalization with Res. Au4f core level spectra are all composed of two spin-orbit doublets $\left(\mathrm{Au}_{4} \mathrm{f}_{7 / 2}, \mathrm{Au} 4 \mathrm{f}_{5 / 2}\right)$; the more intense $\mathrm{Au4f} \mathrm{f}_{7 / 2}$ component, due to metallic $\mathrm{Au}(0)$ atoms, is usually taken as reference $(\mathrm{BE}=83.92 \mathrm{eV})$. As expected for small nanoparticles, the high surface to volume ratio allows us to observe also the Au4f signal related to substrate-thiol interface atoms [50]: the spin-orbit pairs at higher BE values $\left(\mathrm{Au}_{4} \mathrm{f}_{7 / 2}=84.8 \mathrm{eV}\right)$ clearly appear as a pronounced shoulder on all the measured spectra.

\subsubsection{FT-IR Characterization}

The FT-IR spectra of samples AuNPs, AuNPs@RSV1 and AuNPs@RSV2 were recorded in order to detect the functional groups present on the AuNPs surface and hence the molecules anchored; results are shown in Figure 4.

The main peaks in the spectrum of AuNPs@RSV1 can be attributed to contributions from the cit anion. At high wavenumbers (not shown in Figure 4), the peaks located at 3450 and $3200 \mathrm{~cm}^{-1}$ are due to stretching vibration of the $\mathrm{O}-\mathrm{H}$ bond, the peak at $2966 \mathrm{~cm}^{-1}$ to stretching of the C-H bond; all these peaks appear in the same position in the IR spectra of sodium citrate [59]. The intense peaks located at 1575 and $1420-1380 \mathrm{~cm}^{-1}$ are related to asymmetric and symmetric $\mathrm{C}=\mathrm{O}$ stretching vibrations of the carboxylate anion; carboxylates are present in both cit and L-cys in its zwitterionic form. For L-cys, symmetric and asymmetric bending vibrations of the $\mathrm{N}-\mathrm{H}$ bond in the ammonium cation are expected at 1600 and $1545 \mathrm{~cm}^{-1}$ respectively; both peaks can be detected as shoulders on the high and low energy sides of the main peak at $1575 \mathrm{~cm}^{-1}$. Other weak skeletal vibrations at 1280, 1270, 1194, 1150, 1070, 910, $840 \mathrm{~cm}^{-1}$ in the spectrum of AuNPs@Res1 correspond to similar peaks detected in the spectrum of sodium cit, which can be considered the main component of the nanoparticle surface. However, contributions from RSV to the IR spectrum of AuNPs@Res1 could also be expected. The IR spectrum of RSV is dominated by the bands related to the phenol groups. According to literature [60], $C=C$ stretching peaks related to the aromatic rings are found at $1611 \mathrm{~cm}^{-1}$, $1583 \mathrm{~cm}^{-1}$, and $1520 \mathrm{~cm}^{-1}$; these peaks could be partially superimposed on the main asymmetric $\mathrm{C}=\mathrm{O}$ stretching vibration of the carboxylate anion of cit. Moreover, $\mathrm{C}-\mathrm{O}$ stretching and $\mathrm{O}-\mathrm{H}$ bending vibrations of the phenolic hydroxyl group produce intense bands that are found at $1155 \mathrm{~cm}^{-1}$ and $1377 \mathrm{~cm}^{-1}$, respectively; the latter superimposes with the symmetric $\mathrm{C}=\mathrm{O}$ stretching vibration of carboxylate. Finally, the IR spectrum of resveratrol shows peaks at 965,831 and $670 \mathrm{~cm}^{-1}$; the first is typical of alkene in trans-configuration, the second of arenes conjugated to the olefinic groups and the third corresponds to $=\mathrm{C}-\mathrm{H}$ of deformation bands the olefinic group. It is worth noting that weak peaks at 1155, 950, 830 and $630 \mathrm{~cm}^{-1}$ (marked with * in Figure 4) are present in the spectrum and could 
be attributed to RSV. Finally, a low intensity peak can be detected at $1740 \mathrm{~cm}^{-1}$, a feature that can be attributed to $\mathrm{C}=\mathrm{O}$ stretching vibration of the protonated carboxyl group. This peak becomes dominant in the spectra of AuNPs and AuNPs@RSV2, suggesting that the citrate and lysine carboxyls are found in their protonated form. Moreover, in the spectrum AuNPs the peaks at 1575 and $1380 \mathrm{~cm}^{-1}$ related to the deprotonated carboxylate group disappear completely.

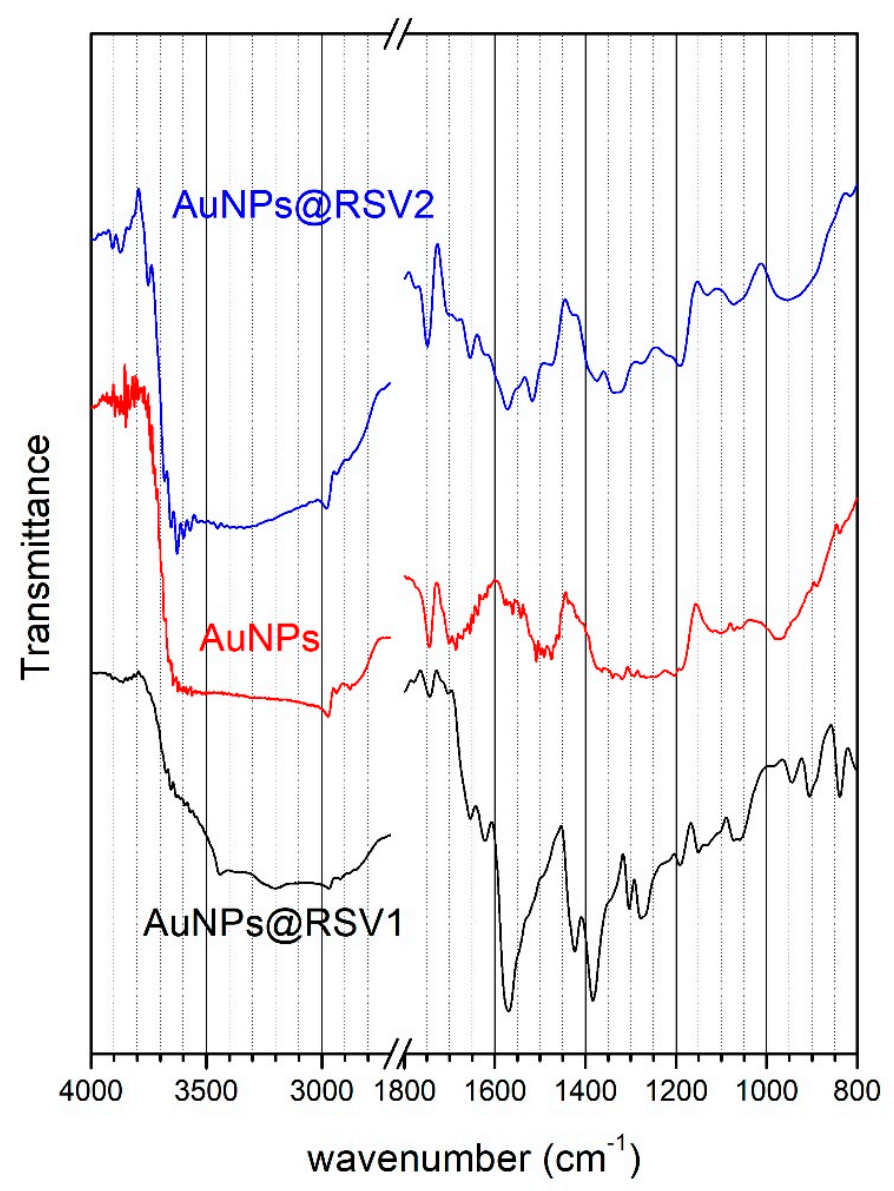

Figure 4. Fourier Transform Infrared Spectroscopy (FT-IR) spectra in the $2000-600 \mathrm{~cm}^{-1}$ range of samples AuNPs, AuNPs@RSV1 and AuNPs@RSV2. Markers represent peaks related to resveratrol.

The spectrum of AuNPs@RSV2 is dominated by the $\mathrm{C}=\mathrm{O}$ stretching peak of protonated carboxyls, with minor contributions at 1650 and $1550 \mathrm{~cm}^{-1}$ that could be related to symmetrical and asymmetrical $\mathrm{N}-\mathrm{H}$ bending of the ammonium cation of L-cys. The intense peak at $1450 \mathrm{~cm}^{-1}$ could indicate the presence of some deprotonated carboxylate anions. At lower wavenumbers, the spectrum shows peaks related to RSV (marked with * in Figure 4) at 1377, 1155, 950, 830 and $630 \mathrm{~cm}^{-1}$, yielding evidence of successful adsorption of the RSV molecule on the AuNPs surface.

\subsubsection{NEXAFS Characterization}

C K edge NEXAFS spectra of AuNPs, shown in Figure 5, were recorded at normal and grazing incidence; however, no angle-dependent effects were detected. 

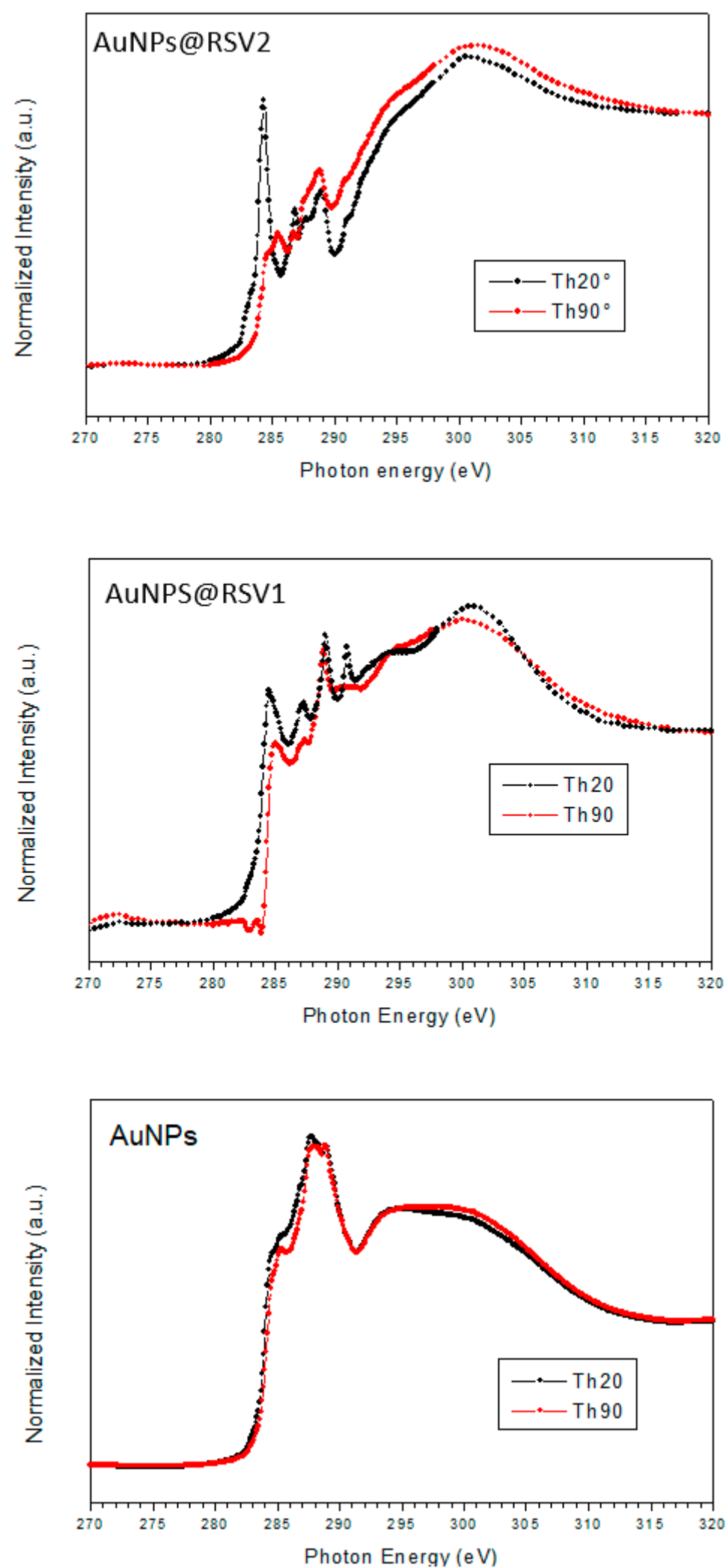

Figure 5. Near Edge X-ray Absorption Fine Structure (NEXAFS) C K edge NEXAFS spectra of samples AuNPs, AuNPs@RSV1 and AuNPs@RSV2 recorded at grazing (Th20) and normal (Th90) incidence.

The spectrum shows two intense peaks located at 287.7 and $288.8 \mathrm{eV}$, with a shoulder at $285.5 \mathrm{eV}$. According to literature, the $1 \mathrm{~s} \rightarrow \pi^{*}$ transition related to the $\mathrm{C}=\mathrm{O}$ bond in the carboxylate of cysteine is 
expected at $288.6 \mathrm{eV}$ [61]; similar values are expected for carboxyl groups [62,63]. Moreover, L-cys is expected to show a $1 \mathrm{~s} \rightarrow \sigma^{*}$ peak related to the C-S bond at about $287.3 \mathrm{eV}$. The broad bands located at about 294 and $300 \mathrm{eV}$ are related to $1 \mathrm{~s} \rightarrow \sigma^{*}$ transitions of $\mathrm{C}-\mathrm{H}$ and $\mathrm{C}=\mathrm{O}$ bonds, respectively [64].

In the spectra of AuNPs@RSV1 and AuNPs@RSV2 relevant changes are evidenced, clearly related to the conjugation of RSV on the nanoparticles surface. RSV (trans-3,5,4-trihydroxystilbene) is a complex molecule, consisting of a phenol and a 1-3 diphenol unity linked through a vinyl group, in a building block approach. According to the literature [64], the $\mathrm{C}$ k edge spectrum of the vinyl moiety should be dominated by the $1 \mathrm{~s} \rightarrow \pi^{*}$ transition related to the $\mathrm{C}=\mathrm{C}$ bond, located at $284.5 \mathrm{eV}$. The phenol moiety presents a more complex spectrum. For the benzene molecule, two distinct $1 \mathrm{~s} \rightarrow \pi^{*}$ transitions are found in the C K edge spectrum $\left(\pi_{1,2}^{*}\right.$ and $\left.\pi_{3}^{*}\right)$, located at about 285.4 and $289.2 \mathrm{eV}$, respectively (small shifts of $\pm 0.2 \mathrm{eV}$ can be detected depending on the aggregation state), the first peak being the most intense. The insertion of a heteroatom as substituent in the benzene ring causes the two mentioned peaks to split in two in systems like aniline or phenol, due to the higher Binding Energy of the carbon directly bonded to the heteroatom $\left(C_{1}\right)$ and of all the other carbons $\left(C_{2,3,4}\right)$. In the spectrum of phenol, four different $1 \mathrm{~s} \rightarrow \pi^{*}$ transitions can be evidenced: $\pi^{*} 1,2\left(\mathrm{C}_{2,3,4}\right)$ at $285.4 \mathrm{eV}, \pi^{*} 2$ $\left(C_{1}\right)$ at $287.2 \mathrm{eV}, \pi^{*} 3\left(\mathrm{C}_{2,3,4}\right)$ at $288.8 \mathrm{eV}, \pi^{*} 3\left(\mathrm{C}_{1}\right)$ at $290.9 \mathrm{eV}$; for all the mentioned peaks small shifts of $\pm 0.2 \mathrm{eV}$ can be detected depending on the aggregation state [64]. In a building block approach, we expect to detect a similar trend for the phenol unity of RSV and for the 1-3 diphenol unity, but with higher intensity for the transitions related to the $\mathrm{C}_{1}$ atom.

The main peaks evidenced in the $284-292 \mathrm{eV}$ region of the $\mathrm{C} k$ edge spectrum of sample AuNPs@RSV1 are located at $284.8 \mathrm{eV}$, with a shoulder at $285.3 \mathrm{eV}$, and at 287.3, 288.9 and $290.7 \mathrm{eV}$ respectively. The first peak results from the superimposition of the $\pi_{1,2}^{*}\left(C_{2,3,4}\right)$ transition of phenol $(285.4 \mathrm{eV})$, with the $\pi^{*}$ peak of vinyl in resveratrol, expected at $284.5 \mathrm{eV}$. The second peak is related to $\pi_{2}^{*}\left(C_{1}\right)$, with possible contributions from the $\sigma^{*}$ peak related to the C-S bond of cysteine, located approximately at the same photon energy. The peak at $288.8 \mathrm{eV}$ results from the $\pi_{3}^{*}\left(\mathrm{C}_{2,3,4}\right)$ peak of resveratrol, but also from substantial contributions of the $\pi^{*} \mathrm{C}=\mathrm{O}$ transitions of cysteine and citrate that, according to FT-IR spectrum, is the main component of the surface of AuNPs@RSV1 nanoparticles. The last peak $(290.7 \mathrm{eV})$ corresponds to the $\pi_{3}^{*}\left(\mathrm{C}_{1}\right)$ peak, with possible contributions from the $\mathrm{K} 2 \mathrm{p}_{3 / 2}$ peak of potassium ions located on the surface, related to the presence of deprotonated citrate molecules, as evidenced by FT-IR spectroscopy.

All the mentioned peaks are clearly evident in the spectrum recorded at grazing incidence (Th20), but when the incidence angle is moved to normal (Th90) the intensity of all the peaks related to the $\pi^{*}$ transitions of resveratrol decreases, with the exception of the peak at $288.8 \mathrm{eV}$, whose intensity is mainly related to the $\pi^{*} \mathrm{C}=\mathrm{O}$ transitions of cysteine and citrate. This result suggests the formation of ordered structures, possibly resulting from partial aggregation of RSV molecules. In the region above $292 \mathrm{eV}$, the two broad bands having $\sigma^{*}$ character located at 294 and $301 \mathrm{eV}$ were already present in the spectrum of AuNPs, and assigned to $1 \mathrm{~s} \rightarrow \sigma^{*}$ transitions of $\mathrm{C}-\mathrm{H}$ and $\mathrm{C}=\mathrm{O}$ bonds, respectively; phenol also shows two $\sigma^{*} \mathrm{C}-\mathrm{C}$ bands in the same position. Slight angular effects are evidenced also on the $\sigma^{*}$ bands intensity.

In the 284-292 eV region of the $C \mathrm{k}$ edge spectrum of sample AuNPs@RSV2, peaks are located at $284.5 \mathrm{eV}$, with a shoulder at $285.3 \mathrm{eV}, 286.7 \mathrm{eV}, 288.8 \mathrm{eV}$, with a shoulder at $287.6 \mathrm{eV}$ and a low intensity peak $290.6 \mathrm{eV}$. The features are similar to the ones evidenced in the spectrum of AuNPs@RSV1, without contributions from K2p signals. However, the angle dependency of the $\pi^{*}$ transitions, when the incidence angle is changed from grazing to normal, is striking, strongly suggesting the formation of ordered resveratrol aggregates on the AuNPs surface; this phenomenon appears more pronounced for AuNPs@RSV2 than for sample AuNPs@RSV1, due to the different preparation methodology, suggesting the formation of larger aggregates. This result confirms the previously discussed XPS and FT-IR data, which evidenced the formation of RSV aggregates on the AuNPs surface because of physisorption for sample AuNPs@RSV2. 


\subsection{AuNPs and AuNPs@RSV Biocompatibility}

Since the AuNPs-RSV2 system proved to be less controlled both dimensionally (DLS data) and structurally (by HR-XPS, FT-IR and NEXAFS data), the investigation on the cellular viability effectiveness of AuNPs was performed in breast cancer cells paralleled with the evaluation of anticancer effects of RSV and AuNPs@RSV1. The estrogen receptor $\alpha$ positive MCF-7, the growth of which is dependent on the hormone $17 \beta$-estradiol (E2), have been used as experimental model. As expected, E2 treatment increased the number of cells (Figure 6a), while the cell stimulation with the apoptosis inducer Staurosporin (STS) strongly reduced cell numbers. Notably, none of AuNPs concentration tested (i.e., 1.0-45.5 $\mu \mathrm{g} / \mathrm{mL}$ ) modified MCF-7 morphology (data not shown) or their vitality (Figure 6a). The AuNPs effect on cell vitality has been further confirmed evaluating the activation of poly (ADP-ribose) polymerase-1 (PARP-1) cleavage (Figure 6b). PARP-1, a DNA-binding enzyme involved in DNA damage processing, is one of several known cellular substrates of caspases. Cleavage of PARP-1 by caspases is a hallmark of the process of programmed cell death or apoptosis [65]. Only the apoptotic inducer (i.e., STS) promotes PARP-1 cleavage increasing, in a dose-dependent manner, the level of $89 \mathrm{kDa}$ band, while concentrations of AuNPs significantly modify the level of cleaved PARP-1 (Figure 6b). These results sustain the incapability of AuNPs to trigger a stress-dependent signal transduction pathway that culminates in the activation of apoptotic cascade.

\section{a)}

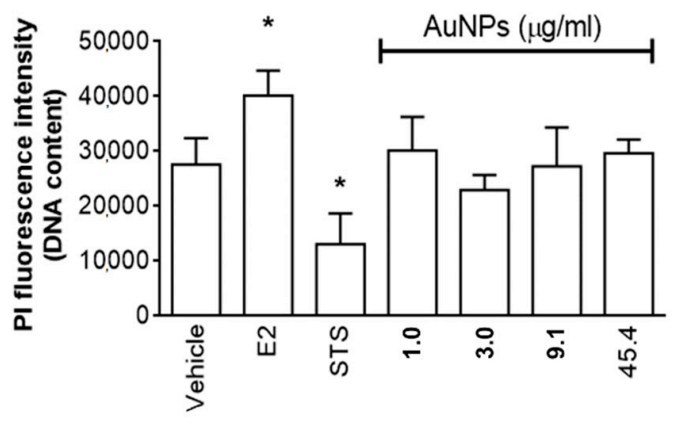

b)
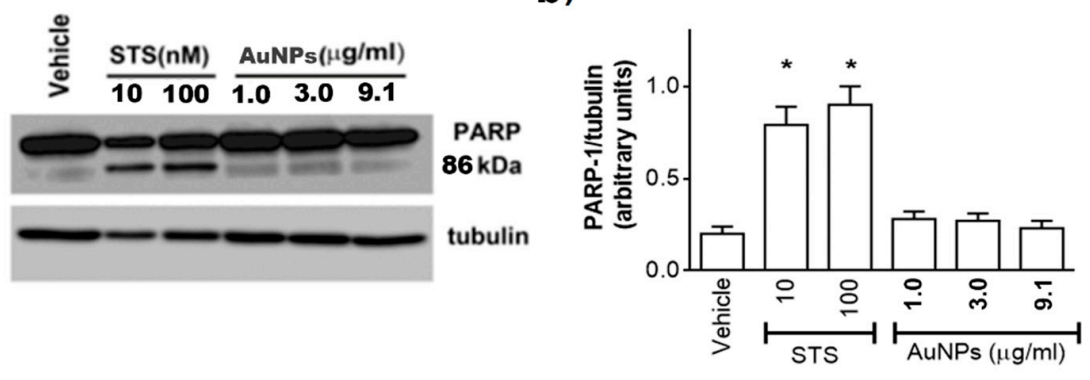

Figure 6. Analyses of cellular DNA content obtained from propidium iodine assay (PI). (a) MCF-7 cells were treated for $48 \mathrm{~h}$ with either vehicle (ethanol/DMEM, 1/10) or E2 (10 nM) or staurosporine (100 nM; STS) or with different AuNPs concentrations. Data are means \pm SD of six different experiments. $\left.{ }^{*}\right) p<0.001$ was calculated with Student's $t$ test versus vehicle. (b) Western blot (left) and densitometric analyses (right) of PARP-1 cleavage in MCF-7 cells. Cells were treated with staurosporine (10 or $100 \mathrm{nM}$, STS) or with different AuNPs concentrations. The amount of cleaved protein was normalized by comparison with $\alpha$-tubulin levels. Data are the mean \pm SD of five different experiments. $\left.{ }^{*}\right) p<0.001$ was determined with Student $t$-test with respect to the vehicle.

The efficacy of AuNPs@RSV1 as an anti-tumor agent was successively evaluated. The extensive anticancer effects ascribed to RSV seem to depend on several action mechanisms, the activation of which depends on RSV concentration. Indeed, RSV concentrations ranging from 50 to $300 \mu \mathrm{M}$ could 
activate DNA repair mechanisms, modulate cell cycle progression, and influence the expression of apoptosis-related genes [31]. Most investigations have demonstrated that RSV concentrations (i.e., 10-20 $\mu \mathrm{M}$ ) sensitize breast carcinoma cell lines to chemotherapeutic agents such as Paclitaxel by down-regulating surviving expression while increasing apoptosis [66]. RSV concentrations $<10 \mu \mathrm{M}$ (i.e., $0.5-5.0 \mu \mathrm{M}$ ) have been reported to interfere with estrogen receptor $\alpha$ subtype activities devoted to E2-dependent breast cancer cell growth and survival [31]. Thus, to obtain more information on RSV action mechanisms, the AuNPs@RSV1 were produced by using specific amounts of RSV molecules (i.e., $0.5-10 \mu \mathrm{M}$ ) during AuNPs synthesis. At only $10 \mu \mathrm{M}$ concentration, RSV reduces MCF-7 number (Figure 7a), whereas AuNPs@RSV1 decreases cell number already at $1.0 \mu \mathrm{M}$ (Figure 7a). The concentration-dependent decrease in cell number induced by AuNPs@RSV1 is not a cytotoxic phenomenon being associated with the activation of the apoptotic cascade, as demonstrated by the PARP-1 cleavage. Indeed, a weak but significant increase of PARP-1 $89 \mathrm{kDa}$ band over the control is induced by stimulating MCF-7 cells with $1.0 \mu \mathrm{M}$ AuNPs@RSV1, while a more robust level of cleaved PARP-1 is present after the treatment of MCF-7 cells with $10 \mu \mathrm{M}$ AuNPs@RSV1 (Figure 7b). Notably, we previously showed that at a concentration of just $10 \mu \mathrm{M}$, RSV alone significantly increases PARP-1 cleavage [31]. The results provide compelling evidence that conjugated RSV maintains its anticancer effects even at very low concentrations, suggesting that the association with AuNPs could enhance RSV entry into the cells, as reported by other authors using gum Arabic stabilized RSV-encapsulated gold nanoparticles [42].

\section{a)}

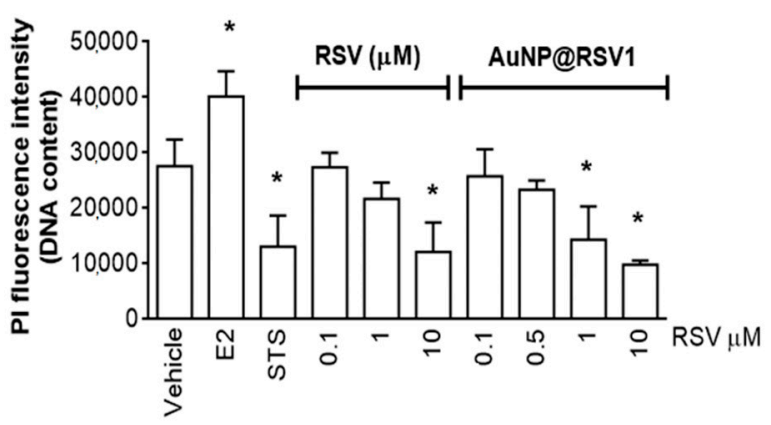

b)
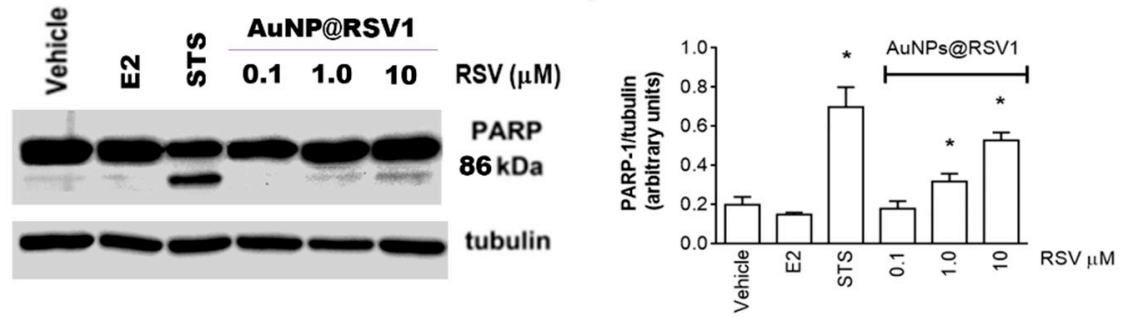

Figure 7. Analyses of cellular DNA content obtained from propidium iodine assay (PI). (a) MCF-7 cells were treated for $48 \mathrm{~h}$ with either vehicle (ethanol/DMEM, 1/10) or E2 (10 nM) or staurosporine (100 nM; STS) or with different RSV or concentrations. Data are means \pm SD of six different experiments. $p<0.001$ was calculated with ANOVA followed by Bonferroni test versus vehicle (a), versus RSV 0.1 and $1 \mu \mathrm{M}(\mathbf{b})$, versus the same concentrations of AuNPS@RSV1 (c), versus AuNPS@RSV1 $0.1 \mu \mathrm{M}$ (d), and versus the same concentrations of RSV (e). (b) Western blot (left) and densitometric analyses (right) of PARP-1 cleavage in MCF-7 cells. Cells were treated with E2 (10 nM) or staurosporine (10 nM, STS) or with different AuNPs@RSV1 concentrations. The amount of cleaved protein was normalized by comparison with $\alpha$-tubulin levels. Data are the mean \pm SD of three different experiments. $\left(^{*}\right) p<0.001$ was determined with Student $t$-test with respect to the vehicle. 


\section{Conclusions}

RSV is one of the most widely studied plant polyphenols for its potential, yet often controversial, health benefits. Nonetheless, most of the many RSV effects reported in in vitro studies have failed to be reproduced in vivo, mainly due to RSV pharmacokinetics. Indeed, in human beings, RSV is highly absorbed orally $(\sim 70 \%)$ yet has poor systemic bioavailability $(\sim 0.5 \%)$, being rapidly metabolized into RSV sulfate and glucuronide conjugates. Furthermore, gut microbiota and genetic background generate a wide range of inter-individual responses upon oral ingestion of RSV. In contrast, in vitro studies have described an array of mechanistic effects that generate controversy given the likely non-physiological concentrations used, as well as the omission of the contribution of RSV metabolites [34]. As for other drugs, the problem could be solved by exploiting highly hydrophilic AuNPs to deliver RSV.

Here, two approaches to produce AuNPs-RSV conjugate were studied in order to obtain a high load of RSV that can be transported and bioavailable. Above all, the interaction of AuNPs with RSV was investigated from a structural point of view, highlighting the key role of the surface of gold that combines RSV with non-covalent interactions. In addition, biological tests were carried out on AuNPs and the best conjugate to verify cytotoxicity and the maintenance of the biological activity of the loaded RSV. Large efforts are currently devoted to understanding the potential adverse effects of NPs on humans. Several key findings have been made recently. Among these, it has been observed that NPs may accumulate in the liver and kidney, triggering oxidative stress, inflammation, and indirect DNA damage in living systems. It has been proposed that once the metallic NPs are taken up in cells, they can release their cargo intracellularly, but the acidic environment of the lysosomes, in which NPs accumulate, triggers the release of relatively toxic ions (e.g., $\mathrm{Ag}^{+}, \mathrm{Au}^{1+/ 3+}$ ions) in the cell that are the true mediators responsible for the observed intracellular toxicity profiles [67]. However, the size, shape, and a stable coating of NPs may have a key role in determining the cellular damage. Indeed, while those effects were very pronounced in small $(13 \mathrm{~nm})$ sized gold nanospheres, citrate-coated $60 \mathrm{~nm}$ nanospheres were much less toxic and did not present most of the above reported organ and cellular alterations and always in a dose dependent manner [68]. In this paper, sphere-shaped $45.0 \mathrm{~nm}$ \pm 12.0 AuNPs and AuNP@RSV1 were synthetized using citrate and L-cysteine as capping agents. None of tested NP concentration (up to $45.5 \mu \mathrm{g}$ ) induced cell death, suggesting that cellular alteration of our nanospheres may be low. These only preliminary in vitro data will need further validation.

Although the ability of AuNPs@RSV to maintain the anticancer effects of RSV against hepatoma and $\mathrm{ER} \alpha$ negative cell lines growth, as well as against breast cancer invasion, has been reported [42,46,47], here our data demonstrated, for the first time, the ability of gold-conjugated RSV to reduce the $\mathrm{ER} \alpha$ positive breast cancer cell number by inducing the activation of PARP-1 cleavage. Although more experiments, currently ongoing in our laboratory, are requested to better elucidate the action mechanisms of RSV released from AuNPs, our data provide compelling evidence that RSV on AuNPs enhances the bioavailability of this stilbene so that therapeutically active species can be optimally available in vivo at physiological concentrations, reducing the inter-individual differences and opening new avenues for applications in therapies against human diseases.

Supplementary Materials: The following are available online at http://www.mdpi.com/2079-4991/10/10/1898/s1, Figure S1: Calibration curve of RSV in water; Figure S2: O1s, N1s, S2p and Au4f XPS spectra of AuNPs@RSV1; Table S1. XPS BE, FWHM, Atomic Percent values and Assignments.

Author Contributions: Conceptualization, I.V. and C.B. and M.M.; chemical synthesis and Uv-vis characterizations, I.V.; FT-IR and NEXAFS measurements and elaboration G.I.; DLS measurements and elaboration, I.F.; SR-XPS measurements and elaborations C.B. and V.S.; biological studies, M.C., E.M. and M.M.; original draft preparation and editing, I.V.; review by all authors. All authors have read and agreed to the published version of the manuscript.

Funding: This research was funded by Grants PRIN 2017 n²017SNRXH3.

Acknowledgments: The Grants PRIN 2017 n²017SNRXH3 to MM and the grant of Excellence Departments, MIUR (ARTICOLO 1, COMMI 314-337 LEGGE 232/2016) to authors of Roma Tre University are gratefully acknowledged.

Conflicts of Interest: The authors declare no conflict of interest. 


\section{References}

1. Jayalekshmi, A.C.; Sharma, C.P. Gold nanoparticle incorporated polymer/bioactive glass composite for controlled drug delivery application. Colloids Surf. B 2015, 126, 280-287. [CrossRef] [PubMed]

2. Zhao, Q.; Yang, Y.; Wang, H.; Lei, W.; Liu, Y.; Wang, S. Gold nanoparticles modified hollow carbon system for dual-responsive release and chemo-photothermal synergistic therapy of tumor. J. Colloid Interf. Sci. 2019, 554, 239-249. [CrossRef] [PubMed]

3. Dreaden, E.C.; Alkilany, A.M.; Huang, X.; Murphy, C.J.; El-Sayed, M.A. The golden age: Gold nanoparticles for biomedicine. Chem. Soc. Rev. 2012, 41, 2740-2779. [CrossRef] [PubMed]

4. Fratoddi, C.A.; Venditti, I.; Catone, D.; O’Keeffe, P.; Paladini, A.; Toschi, F.; Turchini, S.; Sciubba, F.; Testa, G.; Battocchio, C.; et al. Gold nanoparticles functionalized by rhodamine B isothiocyanate to tune plasmonic effects. J. Colloid Interf. Sci. 2018, 513, 10-19. [CrossRef]

5. Mieszawska, A.J.; Mulder, W.J.M.; Fayad, Z.A.; Cormode, D.P. Multifunctional gold nanoparticles for diagnosis and therapy of disease. Mol. Pharm. 2013, 10, 831-847. [CrossRef]

6. Hitchcock, J.; White, A.L.; Hondow, N.; Hughes, T.A.; Dupont, H.; Biggs, S.; Cayre, O.J. Metal-shell nanocapsules for the delivery of cancer drugs. J. Colloid Interf. Sci. 2020, 567, 171-180. [CrossRef]

7. Vigderman, L.; Zubarev, E.R. Therapeutic platforms based on gold nanoparticles and their covalent conjugates with drug molecules. Adv. Drug Deliv. Rev. 2013, 65, 663-676. [CrossRef]

8. Nabil, G.; Bhise, K.; Sau, S.; Atef, M.; El-Banna, H.A.; Iyer, A.K. Nano-engineered delivery systems for cancer imaging and therapy: Recent advances, future direction and patent evaluation. Drug Discov. Today 2019, 24, 462-491. [CrossRef]

9. Zhang, X.; Wu, F.; Liu, P.; Gu, N.; Chen, Z. Enhanced fluorescence of gold nanoclusters composed of $\mathrm{HAuCl}_{4}$ and histidine by glutathione: Glutathione detection and selective cancer cell imaging. Small 2014, 10, 5170-5177.

10. Patra, J.K.; Das, G.; Fraceto, L.F.; Campos, E.V.R.; Rodriguez-Torres, M.; Acosta-Torres, L.S.; Diaz-Torres, L.A.; Grillo, R.; Swamy, M.K.; Sharma, S.; et al. Nano based drug delivery systems: Recent developments and future prospects. J. Nanobiotechnol. 2018, 16, 71. [CrossRef]

11. Kalepu, S.; Manthina, M.; Padavala, V. Oral lipid-based drug delivery systems-An overview. Acta Pharm. Sin. B 2013, 3, 361-372. [CrossRef]

12. Chenthamara, D.; Subramaniam, S.; Ramakrishnan, S.G.; Krishnaswamy, S.; Essa, M.M.; Lin, F.; Qoronfleh, M.W. Therapeutic efficacy of nanoparticles and routes of administration. Biomater. Res. 2019, 23, 20. [CrossRef] [PubMed]

13. Frtús, A.; Smolková, B.; Uzhytchak, M.; Lunova, M.; Jirsa, M.; Kubinová, Š.; Dejneka, A.; Lunov, O. Analyzing the mechanisms of iron oxide nanoparticles interactions with cells: A road from failure to success in clinical applications. J. Control. Release 2020, 328, 59-77. [CrossRef] [PubMed]

14. Hua, S.; de Matos, M.B.C.; Metselaar, J.M.; Storm, G. Current Trends and Challenges in the Clinical Translation of Nanoparticulate Nanomedicines: Pathways for Translational Development and Commercialization. Front. Pharmacol. 2018, 9, 790. [CrossRef] [PubMed]

15. Kim, Y.J.; Kim, B.; Kim, J.W.; Nam, G.; Jang, H.S.; Kang, S.W.; Jeong, U. Combination of nanoparticles with photothermal effects and phase-change material enhances the non-invasive transdermal delivery of drugs. Colloids Surf. B 2015, 135, 324-331. [CrossRef] [PubMed]

16. Farina, N.H.; Zingiryan, A.; Vrolijk, M.A.; Perrapato, S.D.; Ades, S.; Stein, G.S.; Lian, J.B.; Landry, C.C. Nanoparticle-based targeted cancer strategies for non-invasive prostate cancer intervention. J. Cell. Physiol. 2018, 233, 6408-6417. [CrossRef]

17. Venditti, I. Morphologies and functionalities of polymeric nanocarriers as chemical tools for drug delivery: A review. J. King Saud Univ. Sci. 2019, 31, 398-411. [CrossRef]

18. Canet-Ferrer, J.; Albella, P.; Ribera, A.; Usagre, J.V.; Maier, S.A. Hybrid magnetite-gold nanoparticles as bifunctional magnetic-plasmonic systems: Three representative cases. Nanoscale Horiz. 2017, 2, $205-216$. [CrossRef]

19. Fratoddia, I.; Venditti, I.; Cametti, C.; Russo, M.V. Gold nanoparticles and gold nanoparticle-conjugates for delivery of therapeutic molecules. Progress and challenges. J. Mater. Chem. B 2014, 2, 4204-4220. [CrossRef]

20. Venditti, I. Engineered gold-based nanomaterials: Morphologies and functionalities in biomedical applications. A mini review. Bioengineering 2019, 6, 53. [CrossRef] 
21. Peng, J.; Liang, X. Progress in research on gold nanoparticles in cancer management. Medicine 2019, 98, e15311. [CrossRef] [PubMed]

22. Zhang, J.; Mou, L.; Jiang, X. Surface chemistry of gold nanoparticles for health related applications. Chem. Sci. 2020, 11, 923-936. [CrossRef]

23. Maccora, D.; Dini, V.; Battocchio, C.; Fratoddi, I.; Cartoni, A.; Rotili, D.; Castagnola, M.; Faccini, R.; Bruno, I.; Scotognella, T.; et al. Gold nanoparticles and nanorods in nuclear medicine: A mini review. Appl. Sci. 2019, 9, 3232. [CrossRef]

24. Yen, H.-J.; Young, Y.-A.; Tsai, T.-N.; Cheng, K.-M.; Chen, X.-A.; Chen, Y.-C.; Chen, C.-C.; Young, J.-J.; Hong, P.-D. Positively charged gold nanoparticles capped with folate quaternary chitosan: Synthesis, cytotoxicity, and uptake by cancer cells. Carbohydr. Polym. 2018, 183, 140-150. [CrossRef]

25. Verma, A.; Stellacci, F. Effect of Surface Properties on Nanoparticle-Cell Interactions. Small 2010, 6, $12-21$. [CrossRef] [PubMed]

26. Fantini, M.; Benvenuto, M.; Masuelli, L.; Frajese, G.V.; Tresoldi, I.; Modesti, A.; Bei, R. In vitro and in vivo antitumoral effects of combinations of polyphenols, or polyphenols and anticancer drugs: Perspectives on cancer treatment. Int. J. Mol. Sci. 2015, 16, 9236-9282. [CrossRef] [PubMed]

27. Cipolletti, M.; Fernandez, V.S.; Montalesi, E.; Marino, M.; Fiocchetti, M. Beyond the Antioxidant Activity of Dietary Polyphenols in Cancer: The Modulation of Estrogen Receptors (ERs) Signaling. Int. J. Mol. Sci. 2018, 19, 2624. [CrossRef] [PubMed]

28. Alamolhodaei, N.S.; Tsatsakis, A.M.; Ramezani, M.; Hayes, A.W.; Karimi, G. Resveratrol as MDR reversion molecule in breast cancer: An overview. Food Chem. Toxicol. 2017, 103, 223-232. [CrossRef] [PubMed]

29. Carter, L.G.; D'Orazio, J.A.; Pearson, K.J. Resveratrol and cancer: Focus on in vivo evidence. Endocr. Relat. Cancer 2014, 21, R209-R225. [CrossRef]

30. Guthrie, A.R.; Chow, H.S.; Martinez, J.A. Effects of resveratrol on drug- and carcinogen-metabolizing enzymes, implications for cancer prevention. Pharmacol. Res. Perspect. 2017, 5, e00294. [CrossRef]

31. Cipolletti, M.; Montalesi, E.; Nuzzo, M.T.; Fiocchetti, M.; Ascenzi, P.; Marino, M. Potentiation of paclitaxel effect by resveratrol in human breast cancer cells by counteracting the $17 \beta$-estradiol/estrogen receptor

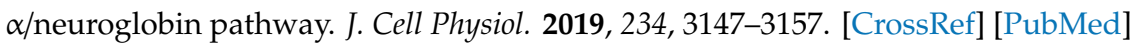

32. Luca, S.V.; Macovei, I.; Bujor, A.; Miron, A.; Skalicka-Woźniak, K.; Aprotosoaie, A.C.; Trifan, A. Bioactivity of dietary polyphenols: The role of metabolites. Crit. Rev. Food Sci. Nutr. 2020, 60, 626-659. [CrossRef] [PubMed]

33. Han, G.; Xia, J.; Gao, J.; Inagaki, Y.; Tang, W.; Kokudo, N. Anti-tumor effects and cellular mechanisms of resveratrol. Drug Discov. Ther. 2015, 9, 1-12. [CrossRef] [PubMed]

34. Springer, M.; Moco, S. Resveratrol and Its Human Metabolites-Effects on Metabolic Health and Obesity. Nutrients 2019, 11, 143. [CrossRef]

35. Soo, E.; Thakur, S.; Qu, Z.; Jambhrunkar, S.; Parekh, H.S.; Popat, A. Enhancing delivery and cytotoxicity of resveratrol through a dual nanoencapsulation approach. J. Colloid Interf. Sci. 2016, 462, 368-374. [CrossRef]

36. Fratoddi, I.; Benassi, L.; Botti, E.; Vaschieri, C.; Venditti, I.; Bessar, H.; Samir, M.A.; Azzoni, P.; Magnoni, C.; Costanzo, A.; et al. Effects of topical methotrexate loaded gold nanoparticle in cutaneous inflammatory mouse model. Nanomed. NBM Nanotechnol. Biol. Med. 2019, 17, 276-286. [CrossRef] [PubMed]

37. Yook, S.; Cai, Z.; Lu, Y.; Winnik, M.A.; Pignol, J.-P.; Reilly, R.M. Intratumorally Injected 177 Lu-Labeled Gold Nanoparticles: Gold Nanoseed Brachytherapy with Application for Neoadjuvant Treatment of Locally Advanced Breast Cancer. J. Nucl. Med. 2016, 57, 936-942. [CrossRef]

38. Borah, P.K.; Das, A.S.; Mukhopadhyay, R.; Sarkar, A.; Duary, R.K. Macromolecular design of folic acid functionalized amylopectin-albumin core-shell nanogels for improved physiological stability and colon cancer cell targeted delivery of curcumin. J. Colloid Interf. Sci. 2020, 580, 561-572. [CrossRef]

39. Khan, S.; Cabe, J.M.; Hill, K.; Beales, P.A. Biodegradable hybrid block copolymer-lipid vesicles as potential drug delivery systems. J. Colloid Interf. Sci. 2020, 562, 418-428. [CrossRef]

40. Fratoddi, I.; Venditti, I.; Battocchio, C.; Carlini, L.; Porchia, M.; Tisato, F.; Bondino, F.; Magnano, E.; Pellei, M.; Santini, C. Highly hydrophilic gold nanoparticles as carrier for anticancer copper(I) complexes: Loading and release studies for biomedical applications. Nanomaterials 2019, 9, 772. [CrossRef] 
41. Lee, S.B.; Ahn, S.B.; Lee, S.-W.; Jeong, S.Y.; Ghilsuk, Y.; Ahn, B.-C.; Kim, E.-M.; Jeong, H.-J.; Lee, J.; Lim, D.-K.; et al. Radionuclide-embedded gold nanoparticles for enhanced dendritic cell-based cancer immunotherapy, sensitive and quantitative tracking of dendritic cells with PET and Cerenkov luminescence. NPG Asia Mater. 2016, 8, e281. [CrossRef]

42. Thipe, V.C.; Amiri, K.P.; Bloebaum, P.; Karikachery, A.R.; Khoobchandani, M.; Katti, K.K.; Jurisson, S.S.; Katti, K.V. Development of resveratrol-conjugated gold nanoparticles: Interrelationship of increased resveratrol corona on anti-tumor efficacy against breast, pancreatic and prostate cancers. Intern. J. Nanomed. 2019, 14, 4413-4428. [CrossRef] [PubMed]

43. Park, S.; Cha, S.H.; Cho, I.; Park, S.; Park, Y.; Cho, S.; Park, Y. Antibacterial nanocarriers of resveratrol with gold and silver nanoparticles. Mater. Sci. Eng. C Mater. Biol. Appl. 2016, 58, 1160-1169. [CrossRef] [PubMed]

44. Mohanty, R.K.; Thennarasu, S.; Mandal, A.B. Resveratrol stabilized gold nanoparticles enable surface loading of doxorubicin and anticancer activity. Colloids Surf. B 2014, 114, 138-143. [CrossRef]

45. Salem, H.F.; Kharshoum, R.M.; Abou-Taleb, H.A.; Naguib, D.M. Brain targeting of resveratrol through intranasal lipid vesicles labelled with gold nanoparticles: In vivo evaluation and bioaccumulation investigation using computed tomography and histopathological examination. J. Drug Target. 2019, 27, 1127-1134. [CrossRef]

46. Zhang, D.; Zhang, J.; Zeng, J.; Li, Z.; Zuo, H.; Huang, C.; Zhao, X. Nano-Gold Loaded with Resveratrol Enhance the Anti-Hepatoma Effect of Resveratrol In Vitro and In Vivo. J. Biomed. Nanotechnol. 2019, 15, 288-300. [CrossRef]

47. Park, S.Y.; Chae, S.Y.; Park, J.O.; Lee, K.J.; Park, G. Gold-conjugated resveratrol nanoparticles attenuate the invasion and MMP-9 and COX-2 expression in breast cancer cells. Oncol. Rep. 2016, 35, 3248-3256. [CrossRef]

48. Dong, Y.; Wan, G.; Yan, P.; Qian, C.; Li, F.; Peng, G. Fabrication of resveratrol coated gold nanoparticles and investigation of their effect on diabetic retinopathy in streptozotocin induced diabetic rats. J. Photochem. Photobiol. B 2019, 195, 51-57. [CrossRef]

49. De Angelis, R.; Venditti, I.; Fratoddia, I.; De Matteis, F.; Prosposito, P.; Cacciotti, I.; D'Amico, L.; Nanni, F.; Yadav, A.; Casalboni, M.; et al. From nanospheres to microribbons: Self-assembled Eosin Y doped PMMA nanoparticles as photonic crystals. J. Colloid Interf. Sci. 2014, 414, 24-32. [CrossRef]

50. Venditti, I.; Testa, G.; Sciubba, F.; Carlini, L.; Secchi, V.; Krause, S.; Meneghini, C.; Mobilio, S.; Battocchio, C.; Fratoddi, I. Hydrophilic metal nanoparticles functionalized by 2-diethylaminoethane thiol: A close look on the metal-ligand interaction and interface chemical structure. J. Phys. Chem. C 2017, 121, 8002-8013. [CrossRef]

51. Sarangi, S.N.; Hussaini, A.M.P.; Sahu, S.N. Strong UV absorption and emission from L-cysteine capped monodispersed gold nanoparticles. Appl. Phys. Lett. 2009, 95, 073109. [CrossRef]

52. Rossi, S.; Donadio, S.; Fontana, L.; Porcaro, F.; Battocchio, C.; Venditti, I.; Bracci, L.; Fratoddi, I. Negatively charged gold nanoparticles as dexamethasone carrier: Stability and citotoxic activity. RCS Adv. 2016, 6, 99016-99022.

53. Freese, C.; Uboldi, C.; Gibson, M.I.; Unger, R.E.; Weksler, B.B.; Romero, I.A.; Couraud, P.-O.; Kirkpatrick, C.J. Uptake and cytotoxicity of citrate-coated gold nanospheres: Comparative studies on human endothelial and epithelial cells. Part. Fibre Toxicol. 2012, 9, 23. [CrossRef]

54. Guo, J.; Armstrong, M.J.; O’Driscoll, C.M.; Holmes, J.D.; Rahme, K. Positively charged, surfactant-free gold nanoparticles for nucleic acid delivery. RSC Adv. 2015, 5, 17862-17871. [CrossRef]

55. NIST X-ray Photoelectron Spectroscopy Database, Version 4.1 (National Institute of Standards and Technology, Gaithersburg, 2012). Available online: http://srdata.nist.gov/xps/ (accessed on 20 July 2020).

56. Secchi, V.; Franchi, S.; Ciccarelli, D.; Dettin, M.; Zamuner, A.; Serio, A.; Iucci, G.; Battocchio, C. Biofunctionalization of $\mathrm{TiO} 2$ Surfaces with Self-Assembling Layers of Oligopeptides Covalently Grafted to Chitosan. ACS Biomater. Sci. Eng. 2019, 5, 2190-2199. [CrossRef]

57. Carlini, L.; Fasolato, C.; Postorino, P.; Fratoddi, I.; Venditti, I.; Testa, G.; Battocchio, C. Comparison between silver and gold nanoparticles stabilized with negatively charged hydrophilic thiols: SR/XPS and SERS as probes for structural differences and similarities. Colloid Surf. A 2017, 532, 183-188. [CrossRef]

58. Secchi, V.; Franchi, S.; Santi, M.; Dettin, M.; Zamuner, A.; Iucci, G.; Battocchio, C. Self-Assembling Behaviour of Cysteine-Modified Oligopeptides: An XPS and NEXAFS Study. J. Phys. Chem. C 2018, 122, 6236-6239. [CrossRef] 
59. Spectral Database for Organic Compounds. National Institute of Advanced Industrial Science and Technology (AIST), Japan. Available online: https://sdbs.db.aist.go.jp/sdbs/cgi-bin/cre_index.cgi (accessed on 20 July 2020).

60. Porto, C.C.M.; Nascimento, T.G.; Oliveira, J.M.S.; Freitas, P.H.; Haimeur, A.; França, R. Use of polyphenols as a strategy to prevent bond degradation in the dentin-resin interface. Eur. J. Oral Sci. 2018, 126, 146-158. [CrossRef]

61. Zubavichus, Y.; Shaporenko, A.; Grunze, M.; Zharnikov, M. NEXAFS spectroscopy of biological molecules: From aminoacids to functional proteins. Nucl. Instrum. Methods Phys. Res. A 2009, 603, 111-114. [CrossRef]

62. Stohr, J. NEXAFS Spectroscopy. In Springer Series in Surface Sciences; Gomer, C., Ed.; Springer: Berlin, Germany, 1991.

63. Outka, D.A.; Stohr, J.; Madix, R.J.; Rotermund, H.H.; Hermsmeier, B.; Solomon, J. NEXAFS Studies of complex alcohols and carboxylic acids on the $\operatorname{Si}(111)(7 \times 7)$ surface. Surf. Sci. 1987, 185, 53-74. [CrossRef]

64. Solomon, J.; Madix, R.J.; Stohr, J. Orientation and absolute coverage of benzene, aniline, and phenol on $\operatorname{Ag}(110)$ determined by NEXAFS and XPS. Surf. Sci. 1991, 255, 12-30. [CrossRef]

65. Chaitanya, G.V.; Steven, A.J.; Babu, P.P. PARP-1 cleavage fragments: Signatures of cell-death proteases in neurodegeneration. Cell Commun. Signal. 2010, 8, 31. [CrossRef] [PubMed]

66. Fulda, S.; Debatin, K.M. Sensitization for anticancer drug-induced apoptosis by the chemopreventive agent resveratrol. Oncogene 2004, 23, 6702-6711. [CrossRef] [PubMed]

67. Sabella, S.; Carney, R.P.; Brunetti, V.; Malvindi, M.A.; Al-Juffali, N.; Vecchio, G.; Janes, S.M.; Bakr, O.M.; Cingolani, R.; Stellacci, F.; et al. A general mechanism for intracellular toxicity of metal-containing nanoparticles. Nanoscale 2014, 6, 7052-7061. [CrossRef]

68. Enea, M.; Pereira, E.; de Almeida, M.P.; Araújo, A.M.; Bastos, M.d.; Carmo, H. Gold Nanoparticles Induce Oxidative Stress and Apoptosis in Human Kidney Cells. Nanomaterials 2020, 10, 995. [CrossRef]

(C) 2020 by the authors. Licensee MDPI, Basel, Switzerland. This article is an open access article distributed under the terms and conditions of the Creative Commons Attribution (CC BY) license (http://creativecommons.org/licenses/by/4.0/). 